Check for updates

Cite this: RSC Adv., 2018, 8, 36167

\title{
Efficient production of high-molecular-weight hyaluronic acid with a two-stage fermentation
}

\begin{abstract}
J. Liu, Y. Wang, (D) Z. Li, Y. Ren, Y. Zhao and G. Zhao
In this paper, the production pattern of hyaluronic acid $(\mathrm{HA})$ was revealed: the chain growth of HA mainly occurred in the first half of fermentation while the product accumulated throughout the fermentation period. Attempts were made to develop a two-stage fermentation process which provided high-level synthesis in both product titer and molecular weight. The $\mathrm{pH}$ was kept at 8.0 with a temperature of $31{ }^{\circ} \mathrm{C}$ in the first fermentation stage $(0-10 \mathrm{~h})$ to promote the growth of weight-average molecular weight $\left(M_{w}\right)$, and the $\mathrm{pH}$ and temperature were maintained at 7.0 and $37{ }^{\circ} \mathrm{C}$, respectively, in the following fermentation stage to facilitate HA accumulation. In addition, constant rates of aeration (1 vvm) and agitation (600 rpm) were adopted. The two-stage fermentation provided a balanced result in which a product titer of $4.75 \mathrm{~g} \mathrm{~L}^{-1}$ and a $M_{\mathrm{w}}$ of $2.36 \times 10^{6} \mathrm{Da}$ were achieved under optimized conditions. The process introduces an effective way to produce HA considering the effect of segmented control strategy.
\end{abstract}

Received 3rd September 2018 Accepted 17th October 2018

DOI: $10.1039 / \mathrm{c} 8 \mathrm{ra07349j}$

rsc.li/rsc-advances

aeration and agitation have been considered as influential factors in HA fermentation. ${ }^{6}$ Armstrong and Johns studied the effect of culture conditions on molecular weight property of $\mathrm{HA}$, and the highest $M_{\mathrm{w}}$ was obtained at a high initial glucose concentration $\left(40 \mathrm{~g} \mathrm{~L}^{-1}\right)$ accompanied by moderate aeration ( 0.2 to $1 \mathrm{vvm}) .^{7}$ Vidhya et al. found that sucrose and lactose were better carbon sources than glucose for production of high molecular weight HA. ${ }^{9}$ Vázquez et al. reported the production of HA by Streptococcus zooepidemicus based on protein substrates deriving from Scyliorhinus canicula discards, and the highest HA titer reached $2.66 \mathrm{~g} \mathrm{~L}^{-1}{ }^{10} \mathrm{Kim}$ et al. found the optimized temperature $\left(37^{\circ} \mathrm{C}\right), \mathrm{pH}(7.0)$, agitation speed $(1200$ $\mathrm{rpm})$ and aeration rate $(1.0 \mathrm{vvm})$ contributed to the increase of molecular weight. ${ }^{11}$ Johns et al. reported that high levels of agitation $(600 \mathrm{rpm})$ and aeration $(0.3 \mathrm{vvm})$ efficiently improved the HA titer. ${ }^{12}$ Liu et al. proposed a two-stage culture strategy in which S. zooepidemicus were cultured in a fed-batch mode with sucrose concentration maintained at $1.0 \mathrm{~g} \mathrm{~L}^{-1}$ during $0-8 \mathrm{~h}$ and then batch culture was performed during $8-20 \mathrm{~h}$ with an initial sucrose concentration of $15 \mathrm{~g} \mathrm{~L}^{-1}$. With such two-stage culture strategy, HA production increased significantly, ${ }^{13}$ and the developed culture model provided an alternative strategy for the fermentation processes. Furthermore, it has also been reported that a balanced flux of precursors towards HA biosynthesis was required to increase the molecular weight of HA. ${ }^{14,15}$ However, former studies focused on either HA yield or molecular weight, and the high-level synthesis in both product titer and molecular weight is rarely reported. In this study, we aimed to develop a two-stage fermentation process in which the culture conditions were segmentally controlled to achieve a balanced high result in product titer as well as molecular weight.

Fermentation Engineering Technology Research Center of Heibei Province, College of Bioscience \& Bioengineering, Hebei University of Science and Technology, No. 26 Yuxiang Road, Yuhua District, Shijiazhuang 050000, PR China. E-mail: wangyong0520@foxmail.com 


\section{Methods}

\subsection{Materials, strains and culture media}

BHI (Brain Heart Infusion), YE (yeast extract), tryptone and agar were purchased from Aobox Biotechnology Co., Ltd. (Beijing, China). All other chemicals used were of analytical grade and commercially available.

S. zooepidemicus HA-13-06 (screened by our research group and maintained at the Fermentation Engineering Technology Research Center of Hebei Province, Hebei University of Science and Technology, China) was used in all experiments.

The medium for agar slant contained $2 \mathrm{~g} \mathrm{~L}^{-1}$ glucose, $10 \mathrm{~g} \mathrm{~L}^{-1}$ BHI, $5 \mathrm{~g} \mathrm{~L}^{-1} \mathrm{YE}, 5 \mathrm{~g} \mathrm{~L}^{-1}$ tryptone, $5 \mathrm{~g} \mathrm{~L}^{-1} \mathrm{NaCl}$ and $1.8 \mathrm{~g} \mathrm{~L}^{-1}$ $\mathrm{K}_{2} \mathrm{HPO}_{4}$. The medium for inoculum preparation contained $20 \mathrm{~g}$ $\mathrm{L}^{-1}$ glucose, $10 \mathrm{~g} \mathrm{~L}^{-1} \mathrm{YE}, 5 \mathrm{~g} \mathrm{~L}^{-1}$ tryptone, $0.4 \mathrm{~g} \mathrm{~L}^{-1} \mathrm{MgSO}_{4} \cdot 7 \mathrm{H}_{2} \mathrm{O}$ and $1.8 \mathrm{~g} \mathrm{~L}^{-1} \mathrm{~K}_{2} \mathrm{HPO}_{4}$. The fermentation medium used in a $10 \mathrm{~L}$ fermentor contained $70 \mathrm{~g} \mathrm{~L}^{-1}$ glucose, $10 \mathrm{~g} \mathrm{~L}^{-1} \mathrm{YE}, 5 \mathrm{~g} \mathrm{~L}^{-1}$ tryptone, $0.4 \mathrm{~g} \mathrm{~L}^{-1} \mathrm{MgSO}_{4} \cdot 7 \mathrm{H}_{2} \mathrm{O}$ and $1.8 \mathrm{~g} \mathrm{~L}^{-1} \mathrm{~K}_{2} \mathrm{HPO}_{4}$. The $\mathrm{pH}$ of all culture media was adjusted to 7.2 before sterilization which was performed at $116{ }^{\circ} \mathrm{C}$ for $25 \mathrm{~min}$.

\subsection{Culture conditions}

Stock cultures of strain HA-13-06 were maintained at $4{ }^{\circ} \mathrm{C}$. Inoculum preparation was carried out in $500 \mathrm{ml}$ conical flasks with a working volume of $100 \mathrm{ml}$, which were incubated at $37^{\circ} \mathrm{C}$ and $250 \mathrm{rpm}$ for $24 \mathrm{~h}$ on a rotary shaker. The seed culture was then inoculated into $7 \mathrm{~L}$ fermentation medium in a $10 \mathrm{~L}$ fermentor (SGB-10L, Changzhou Sungod Bio-technology \& Engineering Equipment Co., Ltd., Jiangsu, China) with an inoculation rate of $5 \%(\mathrm{v} / \mathrm{v})$. The temperature, aeration rate and agitation speed were $37{ }^{\circ} \mathrm{C}, 1.0 \mathrm{vvm}$ and $600 \mathrm{rpm}$, respectively, and $4 \mathrm{~mol} \mathrm{~L}^{-1} \mathrm{NaOH}$ was added as a neutralizer to keep the $\mathrm{pH}$ at 7.0.

\subsection{Optimization of fermentation conditions}

In the optimization of fermentation conditions, the effects of main influential factors $(\mathrm{pH}$, temperature, aeration and agitation) on HA fermentation was studied. And different levels of pH (no control, 6.0, 6.5, 7.0, 7.5, 8.0, 8.5 and 9.0), temperature $\left(31{ }^{\circ} \mathrm{C}, 34{ }^{\circ} \mathrm{C}, 37{ }^{\circ} \mathrm{C}\right.$ and $\left.40{ }^{\circ} \mathrm{C}\right)$, aeration rate (0, $0.25 \mathrm{vvm}, 0.5$ vvm, $1 \mathrm{vvm}$ and $1.5 \mathrm{vvm}$ ) and agitation speed (300 rpm, $450 \mathrm{rpm}$, $600 \mathrm{rpm}$ and $750 \mathrm{rpm}$ ) were adopted. Particularly, all experiments were conducted based on batch fermentation process, and other parameters were the same to the basic culture conditions in Section 2.2.

\subsection{Analytical methods}

The samples were drawn from bioreactor at regular intervals to determine the concentrations of biomass, substrate and HA. Glucose were measured by SBA-40C biosensor analyzer (Institute of Biology, Shandong Province Academy of Sciences, Shandong, China), and the fermentation broth was properly diluted before determination. ${ }^{\mathbf{1 6}}$ The cell density was measured by a spectrophotometer (UV-1100, Beijing Eternal Cause Instrument Co., Ltd, China) at $700 \mathrm{~nm}$, and the concentration of dry cell weight (DCW) was obtained according to the correlative relationship between absorbance and DCW concentration. ${ }^{\mathbf{1 7}}$ The carbazole method was adopted to determine the concentration of HA, and the optical density was measured at $525 \mathrm{~nm}$ using D-glucuronic acid as a standard. ${ }^{18} M_{\mathrm{w}}$ of HA was determined according to the viscosity method developed by Laurent. ${ }^{19}$

\section{Results and discussion}

\subsection{Effects of aeration and agitation on HA fermentation}

In order to investigate the effect of aeration on HA fermentation, different aeration rates were adopted as shown in Fig. 1. In aerobic fermentation, the aeration rate has a significant influence on dissolved oxygen level which furtherly affects microbial metabolism. Chong et al. reported that glucose uptake and growth rates increased under aerobic conditions, and the altered metabolism translated into a 50\% increase in HA productivity and more than a doubling in molecular weight from 1.07 to $2.4 \times 10^{6} \mathrm{Da}^{20}$ In this study, as the growth of aeration rate, the DCW concentration first increased up to a maximum then decreased, and the tendency of HA and $M_{\mathrm{w}}$ were similar to that of DCW concentration (Fig. 1). The top values of DCW concentration, HA and $M_{\mathrm{w}}$ reached $9.22 \mathrm{~g} \mathrm{~L}^{-1}$, $4.71 \mathrm{~g} \mathrm{~L}^{-1}$ and $1.63 \times 10^{6} \mathrm{Da}$, respectively. Armstrong et al. found the aerobic fermentation contributed to the increase of HA titer and $M_{\mathrm{w}}$ comparing with anaerobic fermentation, and the final HA concentration increased by $20 \% .^{21}$ Johns et al. also reported the promoting effect of aerobic fermentation on HA titer and yield. ${ }^{12}$ As microbial metabolic efficiency is higher at high dissolved oxygen concentration than that in anaerobic condition, the DCW concentration, HA titer and $M_{\mathrm{w}}$ increased with the growth of aeration rate ranging from $0 \mathrm{vvm}$ to $1 \mathrm{vvm}$. However, when aeration rate increased from $1.0 \mathrm{vvm}$ to $1.5 \mathrm{vvm}$, the DCW concent-ration declined from $9.22 \mathrm{~g} \mathrm{~L}^{-1}$ to $8.94 \mathrm{~g} \mathrm{~L}^{-1}$, and $\mathrm{HA}$ titer and $M_{\mathrm{w}}$ decreased by $12.1 \%$ and $24.5 \%$,

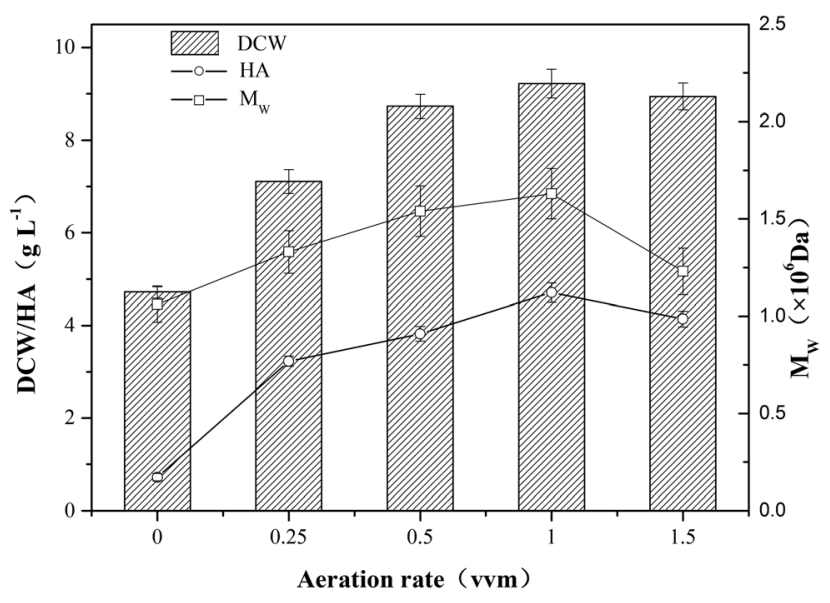

Fig. 1 The fermentation of $\mathrm{HA}$ at different aeration rates ranging from $0 \mathrm{vvm}$ to $1.5 \mathrm{vvm}$. The temperature and agitation speed were maintained at $37^{\circ} \mathrm{C}$ and $600 \mathrm{rpm}$, respectively, and the $\mathrm{pH}$ was kept at 7.0 using $4 \mathrm{~mol} \mathrm{~L}^{-1} \mathrm{NaOH}$ as a neutralizer. A $10 \mathrm{~L}$ fermentor was used, and the error bars in the figure indicate the standard deviations of three parallel replicates. 


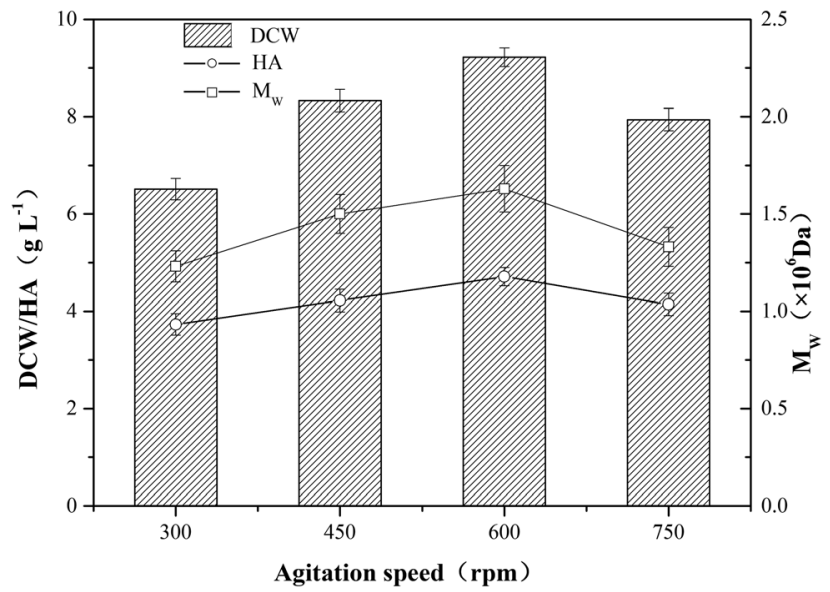

Fig. 2 The fermentation of $\mathrm{HA}$ at different agitation speeds ranging from $300 \mathrm{rpm}$ to $750 \mathrm{rpm}$. The temperature and aeration rate were maintained at $37^{\circ} \mathrm{C}$ and $1.0 \mathrm{vvm}$, respectively, and the $\mathrm{pH}$ was kept at 7.0 using $4 \mathrm{~mol} \mathrm{~L}^{-1} \mathrm{NaOH}$ as a neutralizer. $\mathrm{A} 10 \mathrm{~L}$ fermentor was used, and the error bars in the figure indicate the standard deviations of three parallel replicates.

respectively. It is speculated that the oxygen radical generation in the presence of a large excess of oxygen might have a negative impact on the metabolism of strain HA-13-06, and the degradation of HA polymer chain might further occur. ${ }^{22}$

The influence of agitation on the yield and the molecular weight of HA is complex. ${ }^{23}$ The agitation speed is closely related to the transfer of mass and heat in the HA fermentation broth which is a non-newtonian fluid with high viscosity, and Johns et al. found agitation rate had a profound effect on both the titer and yield of HA produced in anaerobic fermentations. $^{12}$ When the agitation speed rised from $300 \mathrm{rpm}$ to $600 \mathrm{rpm}$, the DCW concentration increased from $6.51 \mathrm{~g} \mathrm{~L}^{-1}$ to $9.20 \mathrm{~g} \mathrm{~L}^{-1}$, however, the DCW concentration decreased $13.9 \%$ when the agitation speed further increased to $750 \mathrm{rpm}$. The tendency of HA titer and $M_{\mathrm{w}}$ were similar to that of DCW concentration (Fig. 2), and the top values of HA titer and $M_{\mathrm{w}}$ were $4.71 \mathrm{~g} \mathrm{~L}^{-1}$ and $1.63 \times 10^{6} \mathrm{Da}$, respectively. As shown in Fig. 2, DCW concentration, HA titer and $M_{\mathrm{w}}$ had a positive correlation with agitation speed ranging from $300 \mathrm{rpm}$ to $600 \mathrm{rpm}$. However, the results indicated that the negative impact exceeded the positive impact of higher agitation speed (750 rpm) on HA production. The shear stress deriving from high agitation speed might damage HA polymer chain and microbial cell, and the oxygen radical generated by the excess of oxygen might cause the degradation of HA. ${ }^{24}$

\subsection{Effect of $\mathrm{pH}$ on $\mathrm{HA}$ fermentation}

In HA fermentation using $S$. zooepidemicus as producer, a sharp drop of $\mathrm{pH}$ was caused by the accumulation of carboxylic acid metabolites mainly composing of lactic acid, and the production of microbial biomass and HA was extremely inhibited by low $\mathrm{pH}$, thus, the adjustment of $\mathrm{pH}$ provided a promoting effect on HA fermentation. ${ }^{25,26}$ As shown in Fig. 3, a significant increase in DCW concentration, HA titer and $M_{\mathrm{w}}$ was observed

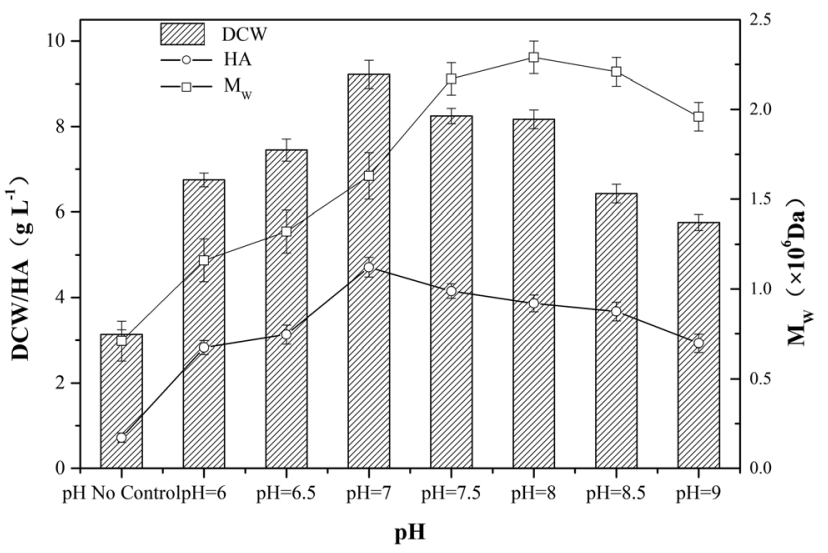

Fig. 3 The fermentation of $\mathrm{HA}$ at different $\mathrm{pH}$ levels (no control, $\mathrm{pH}$ $6.0,6.5,7.0,7.5,8.0,8.5$ and 9.0). The temperature and aeration rate were maintained at $37^{\circ} \mathrm{C}$ and $1.0 \mathrm{vvm}$, respectively, and the agitation speed was kept at $600 \mathrm{rpm}$. A $10 \mathrm{~L}$ fermentor was used, and the error bars in the figure indicate the standard deviations of three parallel replicates.

in experiments with $\mathrm{pH}$ control comparing with no-control condition.

In order to investigate the effect of $\mathrm{pH}$ on HA fermentation, different $\mathrm{pH}$ levels ranging from 6.0 to 9.0 were adopted. With the increase of $\mathrm{pH}$, both DCW concentration and HA titer first increased up to a maximum then decreased, and the top values of DCW concentration and HA titer reached $9.22 \mathrm{~g} \mathrm{~L}^{-1}$ and $4.71 \mathrm{~g} \mathrm{~L}^{-1}$, respectively, when the $\mathrm{pH}$ was kept at 7.0. In addition, the tendency of $M_{\mathrm{w}}$ was similar to that of DCW concentration and HA titer, and the highest $M_{\mathrm{w}}\left(2.29 \times 10^{6} \mathrm{Da}\right)$ was obtained at $\mathrm{pH}$ 8.0. The results indicated that the maximum of HA titer and $M_{\mathrm{w}}$ could not be achieved at the same $\mathrm{pH}$ level.

\subsection{Effect of temperature on HA fermentation}

The catalytic activity of intracellular enzymes in microorganisms is mainly determined by temperature, and the change of temperature has a significant influence on microbial growth and product synthesis. ${ }^{27,28}$ As shown in Fig. 4 , the $M_{\mathrm{w}}$ under different temperatures of $31^{\circ} \mathrm{C}, 34^{\circ} \mathrm{C}, 37^{\circ} \mathrm{C}$ and $40^{\circ} \mathrm{C}$ were 2.34 $\times 10^{6} \mathrm{Da}, 2.18 \times 10^{6} \mathrm{Da}, 1.63 \times 10^{6} \mathrm{Da}$ and $1.38 \times 10^{6} \mathrm{Da}$, respectively. The results indicated that low temperature contributed to the increase of $M_{\mathrm{w}}$. However, when the temperature increased from $31^{\circ} \mathrm{C}$ to $40{ }^{\circ} \mathrm{C}$, both DCW concentration and HA titer first increased up to a maximum then decreased, and the top values of DCW concentration $\left(9.22 \mathrm{~g} \mathrm{~L}^{-1}\right)$ and HA titer $\left(4.71 \mathrm{~g} \mathrm{~L}^{-1}\right)$ were achieved at $37^{\circ} \mathrm{C}$. The maximum of HA titer and $M_{\mathrm{w}}$ could not be achieved at the same temperature, which was similar to the results obtained in $\mathrm{pH}$ optimization.

\subsection{HA production in a two-stage fermentation}

The results obtained in former experiments indicated the top values of HA titer and $M_{\mathrm{w}}$ could be obtained at the same level of aeration rate and agitation speed ( $1 \mathrm{vvm}$ and $600 \mathrm{rpm})$. However, in respect to temperature and $\mathrm{pH}$, the optimized condition for the HA accumulation was at $37^{\circ} \mathrm{C}$ and $\mathrm{pH} 7.0$, and the highest $M_{\mathrm{w}}$ could be obtained at $31{ }^{\circ} \mathrm{C}$ with a pH of 8.0. As 


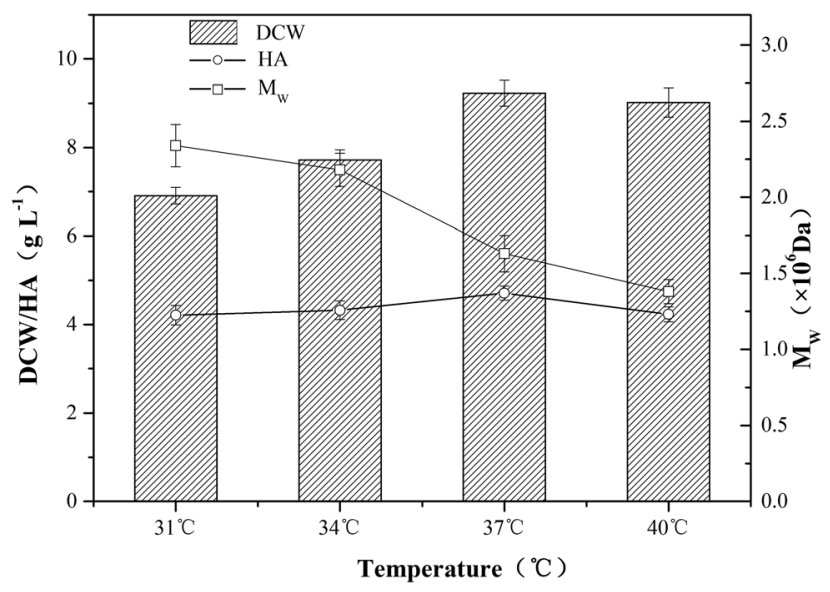

Fig. 4 The fermentation of $\mathrm{HA}$ at different temperatures $\left(31^{\circ} \mathrm{C}, 34^{\circ} \mathrm{C}\right.$, $37^{\circ} \mathrm{C}$ and $40{ }^{\circ} \mathrm{C}$ ). The agitation speed and aeration rate were maintained at $600 \mathrm{rpm}$ and $1.0 \mathrm{vvm}$, respectively, and the $\mathrm{pH}$ was kept at 7.0 using $4 \mathrm{~mol} \mathrm{~L}^{-1} \mathrm{NaOH}$ as a neutralizer. A $10 \mathrm{~L}$ fermentor was used, and the error bars in the figure indicate the standard deviations of three parallel replicates.

shown in Fig. 5A, the glucose concentration continuously decreased from $70.22 \mathrm{~g} \mathrm{~L}^{-1}$ to $2.22 \mathrm{~g} \mathrm{~L}^{-1}$ within $24 \mathrm{~h}$, and the final HA titer reached $4.71 \mathrm{~g} \mathrm{~L}^{-1}$ with a low $M_{\mathrm{w}}$ of $1.63 \times 10^{6} \mathrm{Da}$ under the optimized condition for the HA accumulation $\left(37^{\circ} \mathrm{C}\right.$ and $\mathrm{pH}$ 7.0). However, when the optimized condition $\left(31^{\circ} \mathrm{C}\right.$ and $\mathrm{pH}$ 8.0) promoting $M_{\mathrm{w}}$ growth was adopted, a final $M_{\mathrm{w}}$ of $2.42 \times$ $10^{6} \mathrm{Da}$ was achieved, and the HA titer was only $3.58 \mathrm{~g} \mathrm{~L}^{-1}$ (Fig. 5B), particularly, a residual glucose concentration was $5.13 \mathrm{~g} \mathrm{~L} \mathrm{~L}^{-1}$ which was higher than that obtained under the optimized condition for the HA accumulation indicating a decreased product yield.

By comparing Fig. 5A and $\mathrm{B}$, the $M_{\mathrm{w}}$ mainly increased during the early stage of fermentation $(0-10 \mathrm{~h})$, however, the HA concentration accumulated continuously throughout the fermentation process. In order to obtain the maximum HA titer and highest $M_{\mathrm{w}}$ at the same time, a two-stage fermentation was further conducted. And it is worth to mention that the same aeration rate and agitation speed ( $1 \mathrm{vvm}$ and $600 \mathrm{rpm}$ ) were maintained throughout the fermentation process. As shown in Fig. 5C, in the first stage of fermentation $(0-10 \mathrm{~h})$, the optimized condition for $M_{\mathrm{w}}\left(31^{\circ} \mathrm{C}\right.$ and $\mathrm{pH}$ 8.0) growth was adopted. Before $10 \mathrm{~h}$, an accumulation of $2.99 \mathrm{~g} \mathrm{~L}^{-1} \mathrm{HA}$ was obtained and the $M_{\mathrm{w}}$ reached $2.26 \times 10^{6} \mathrm{Da}$, while the glucose concentration decreased from $70.19 \mathrm{~g} \mathrm{~L}^{-1}$ to $34.54 \mathrm{~g} \mathrm{~L}^{-1}$. In the second stage (10-24 h) which was conducted under the condition $\left(37^{\circ} \mathrm{C}\right.$ and $\mathrm{pH}$ 7.0) promoting HA accumulation, the HA concentration significantly increased from $2.99 \mathrm{~g} \mathrm{~L}^{-1} \mathrm{HA}$ to $4.75 \mathrm{~g} \mathrm{~L}^{-1}$, and a slight increase of $M_{\mathrm{w}}$ (from $2.26 \times 10^{6}$ Da to $2.36 \times 10^{6} \mathrm{Da}$ ) was also observed, particularly, a relative low residual glucose concentration $\left(3.09 \mathrm{~g} \mathrm{~L}^{-1}\right)$ was obtained indicating the efficient conversion. Obviously, the segmented control strategy was effective to increase the efficiency of HA fermentation, and a balanced result containing high levels of both HA titer $\left(4.75 \mathrm{~g} \mathrm{~L}^{-1}\right)$ and $M_{\mathrm{w}}\left(2.36 \times 10^{6} \mathrm{Da}\right)$ was eventually achieved.
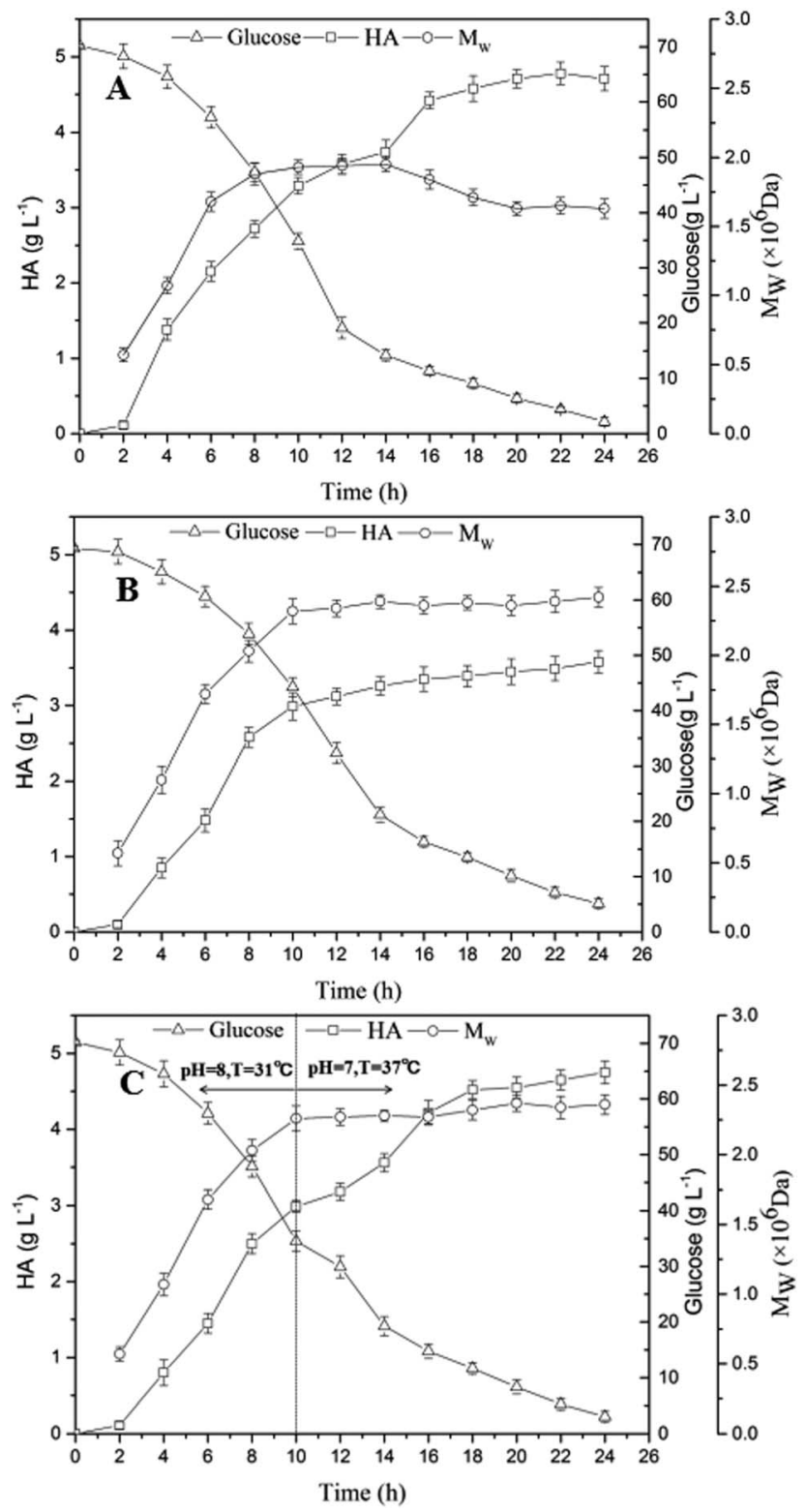

Fig. 5 HA production under different conditions: (A) the optimized condition for the $\mathrm{HA}$ accumulation $\left(37^{\circ} \mathrm{C}\right.$ and $\left.\mathrm{pH} 7.0\right)$, (B) the optimized condition promoting $M_{w}$ growth $\left(31^{\circ} \mathrm{C}\right.$ and $\mathrm{pH} 8.0$ ) and (C) segmented control containing condition (A) (10-24 h) and condition (B) $(0-10 \mathrm{~h})$.

\section{Conclusions}

An efficient way was introduced in this study to efficiently produce high-molecular-weight HA with a two-stage fermentation. The effect of main influential factors $(\mathrm{pH}$, temperature, aeration and agitation) on HA fermentation was studied. The maximum of HA titer and $M_{\mathrm{w}}$ could be obtained at the condition of $1 \mathrm{vvm}$ and $600 \mathrm{rpm}$, and the optimized condition for $M_{\mathrm{w}}$ was found to be $31{ }^{\circ} \mathrm{C}$ and $\mathrm{pH} 8.0$, in addition, the top value of HA titer was obtained at $37{ }^{\circ} \mathrm{C}$ with a $\mathrm{pH}$ of 7.0. In the two-stage fermentation conducted with a segmented control strategy, a balanced result containing high levels of both HA titer and $M_{\mathrm{w}}$ 
was achieved, and the final HA concentration and $M_{\mathrm{w}}$ reached $4.75 \mathrm{~g} \mathrm{~L}^{-1}$ and $2.36 \times 10^{6} \mathrm{Da}$, respectively.

\section{Conflicts of interest}

There are no conflicts to declare.

\section{Acknowledgements}

We would like to acknowledge the establishment of the Fermentation Engineering Technology Research Center of Heibei Province. This work was supported by the Natural Science Foundation of Hebei Province (Grant No. C2016208052).

\section{Notes and references}

1 G. Kogan, L. Šoltés, R. Stern and P. Gemeiner, Biotechnol. Lett., 2007, 29, 17.

2 T. C. Laurent, U. B. G. Laurent and J. R. E. Fraser, Ann. Rheum. Dis., 1995, 54, 429.

3 J. Entwistle, C. L. Hall and E. A. Turley, J. Cell. Biochem., 1996, 61, 569.

4 N. E. Larsen, E. Leshchiner and E. A. Balazs, Mater. Res. Soc. Symp. Proc., 1995, 394, 149.

5 L. E. Freed, G. Vunjak-Novakovic, R. J. Biron, D. B. Eagles, D. C. Lesnoy, S. K. Barlow and R. Langer, Biotechnology, 1994, 12, 689.

6 W. C. Huang, S. J. Chen and T. L. Chen, Biochem. Eng. J., 2006, 32, 239.

7 D. C. Armstrong and M. R. Johns, Appl. Environ. Microbiol., 1997, 63, 2759.

8 E. Shimada and G. Matsumura, J. Biochem., 1975, 78, 513.

9 R. Vidhya, S. Vyas, D. Jain, N. Vedapuri, V. Harshad and K. Arnab, EP2046969B1, 2009.

10 J. A. Vázquez, L. Pastrana, C. Piñeiro, J. A. Teixeira, R. I. Pérez-Martín and I. R. Amado, Mar. Drugs, 2015, 13, 6537.
11 J. H. Kim, S. J. Yoo, D. K. Oh, Y. G. Kweon, D. W. Park, C. H. Lee and G. H. Gil, Enzyme Microb. Technol., 1996, 19, 440.

12 M. R. Johns, L. T. Goh and A. OeggerU, Biotechnol. Lett., 1994, 16, 507.

13 L. Liu, G. Du, J. Chen, M. Wang and J. Sun, Bioresour. Technol., 2008, 99, 8532.

14 W. Y. Chen, E. Marcellin, J. A. Steen and L. K. Nielsen, Mol. Biotechnol., 2014, 56, 147.

15 M. V. Shah, S. S. Badle and K. B. Ramachandran, Biochem. Eng. J., 2013, 80, 53.

16 Y. Wang, D. Cai, M. He, Z. Wang, P. Qin and T. Tan, Bioresour. Technol., 2015, 198, 664.

17 I. R. Amado, J. A. Vázquez, L. Pastrana and J. A. Teixeira, Food Chem., 2016, 198, 54.

18 T. Bitter and H. M. Muir, Anal. Biochem., 1962, 4, 330.

19 T. C. Laurent, M. Ryan and A. Pietruszkiewicz, Biochim. Biophys. Acta, 1960, 42, 476.

20 B. F. Chong, L. M. Blank, R. Mclaughlin and L. K. Nielsen, Appl. Microbiol. Biotechnol., 2005, 66, 341.

21 D. C. Armstrong, M. J. Cooney and M. R. Johns, Appl. Microbiol. Biotechnol., 1997, 47, 309.

22 X. J. Duan, H. X. Niu, W. S. Tan and X. Zhang, J. Microbiol. Biotechnol., 2008, 19, 299.

23 C. G. Boeriu, J. Springer, F. K. Kooy, L. A. M. van den Broek and G. Eggink, Int. J. Carbohydr. Chem., 2013, 2013.

24 X. J. Duan, L. Yang and X. Zhang, J. Microbiol. Biotechnol., 2008, 18, 718.

25 J. F. Lu, Y. Zhu, H. L. Sun, S. Liang, F. F. Leng and H. Y. Li, Lett. Appl. Microbiol., 2016, 62, 316.

26 L. Liu, Y. Liu, J. Li, G. Du and J. Chen, Microb. Cell Fact., 2011, 10, 99.

27 Y. Wang, C. Chen, D. Cai, Z. Wang, P. Qin and T. Tan, Bioresour. Technol., 2016, 218, 1098.

28 D. Vigetti, M. Viola, E. Karousou, G. De Luca and A. Passi, Matrix Biol., 2014, 35, 8. 